\title{
Evaluating Ascorbate Oxidase as a Plant Defense Against Leaf-Chewing Insects Using Transgenic Poplar
}

\author{
Raymond V. Barbehenn • Adam Jaros • Lynn Yip • \\ Lan Tran • Angelos K. Kanellis • C. Peter Constabel
}

Received: 10 June 2008 /Revised: 31 July 2008 / Accepted: 12 August 2008 / Published online: 5 September 2008

(C) Springer Science + Business Media, LLC 2008

\begin{abstract}
Ascorbate is the major water-soluble antioxidant in plants and animals, and it is an essential nutrient for most insect herbivores. Therefore, ascorbate oxidase (AO) has been proposed to function as a plant defense that decreases the availability of ascorbate to insects. This hypothesis was tested by producing transgenic poplar (Populus tremula $\times$ Populus alba; Salicaceae) with 14- to 37 -fold higher foliar AO activities than control (wild type) leaves and feeding these leaves to Lymantria dispar L. (Lepidoptera: Lymantriidae) caterpillars and Melanoplus sanguinipes (Fabricius) (Orthoptera: Acrididae) grasshoppers. To examine potential mechanisms of activity of AO in these insects, ascorbyl radical and/or ascorbate levels were measured in gut contents. No significant changes in ascorbyl radical or ascorbate levels were found in the midgut contents of L. dispar larvae that ingested the leaves of the AOoverexpressing genotypes compared to the control genotype, and no significant decreases in ascorbate levels were found in the foregut or midgut contents of M. sanguinipes.
\end{abstract}

R. V. Barbehenn $(\bowtie) \cdot$ A. Jaros

Departments of Molecular, Cellular and Developmental Biology and Ecology and Evolutionary Biology, University of Michigan, Ann Arbor, MI 48109-1048, USA

e-mail: rvb@umich.edu

L. Yip $\cdot$ L. Tran $\cdot$ C. P. Constabel

Centre for Forest Biology and Department of Biology,

University of Victoria,

P.O. Box 3020, Stn CSC,

Victoria, British Columbia V8W 3N5, Canada

\section{A. K. Kanellis}

Group of Biotechnology of Pharmaceutical Plants,

Laboratory of Pharmacognosy,

Department of Pharmaceutical Sciences,

Aristotle University of Thessaloniki,

54124 Thessaloniki, Greece
Treatment of control leaves with commercial AO also produced no changes in the midgut biochemistry of $L$. dispar larvae, as measured by levels of ascorbyl radicals. Likewise, no increase in oxidative stress was observed in L. dispar that consumed tannin-treated AO-overexpressing leaves compared with tannin-treated control genotype leaves. Performance experiments were carried out on first- and fourthinstar $L$. dispar larvae on leaf disks and on third instars feeding on intact leaves on trees. In no case was a significant difference found in the contrast between the control and three AO-overexpressing genotypes for relative consumption rate, relative growth rate, or nutritional indices. We conclude that elevated levels of AO in poplar are unlikely to serve as a defense against herbivores such as $L$. dispar or $M$. sanguinipes and that the low oxygen levels commonly found in the guts of caterpillars and grasshoppers may limit the activity of ingested $\mathrm{AO}$ in these leaf-chewing insects.

Keywords Lymantria dispar · Lepidoptera · Lymantriidae · Gypsy moth - Melanoplus sanguinipes · Orthoptera ·

Acrididae · Salicaceae $\cdot$ Herbivore $\cdot$ Oxidative stress .

Ascorbic acid · Insect performance

\section{Introduction}

Ascorbate oxidase (AO) catalyzes the oxidation of L-ascorbate $\left(\mathrm{AH}^{-}\right)$to dehydroascorbate (DHA) (overall reaction 1). The production of DHA occurs via the disproportionation of ascorbyl radicals $\left(\mathrm{A}^{\bullet-}\right)$ produced by $\mathrm{AO}$ (reaction 2).

$$
\begin{aligned}
& 2 \mathrm{AH}^{-}+\mathrm{O}_{2}+2 \mathrm{H}^{+} \rightarrow 2 \mathrm{DHA}+2 \mathrm{H}_{2} \mathrm{O} \\
& 2 \mathrm{~A}^{\bullet-}+\mathrm{H}^{+} \rightarrow \mathrm{DHA}+\mathrm{AH}^{-}
\end{aligned}
$$


In plants, AO appears to be located in the cell wall, where it is believed to help regulate cell expansion (Gonzalez-Reyes et al. 1995; Kato and Esaka 2000) and the redox status of the apoplastic space during growth or stress signaling (Pignocchi et al. 2003, 2006; Sanmartin et al. 2003, 2007). In some plants, $\mathrm{AO}$ is also induced by herbivory or wounding and has been proposed to act as an antiherbivore defense (Felton and Summers 1993; Bi and Felton 1995; Bi et al. 1997; Garcia-Pineda et al. 2004). For example, AO in soybean leaves was believed to be responsible for the complete loss of ascorbate from the midgut contents of Helicoverpa zea caterpillars (Felton and Summers 1993). However, demonstration of a direct impact of foliar AO on insect herbivores has been confounded by the many other changes that occur when plants are stressed or induced by herbivory. For example, levels of essential nutrients, secondary chemicals, and many defensive proteins are all commonly altered in herbivore-damaged leaves (e.g., Duffey and Stout 1996; Karban and Baldwin 1997; Hermsmeier et al. 2001; Major and Constabel 2006). Therefore, in this study, AO-overexpressing transgenic poplar trees were produced in order to perform controlled experiments on the potential role of $\mathrm{AO}$ as a plant defense against herbivorous insects.

Tree-feeding caterpillars often ingest high levels of phenolic compounds, and an ascorbate-based antioxidant system is central to the defense of caterpillars against the oxidation of these phenolics caused by the high $\mathrm{pH}$ of the midgut (Felton and Duffey 1992; Barbehenn et al. 2001). In the absence of sufficient ascorbate in the midgut contents, phenolic oxidation produces elevated levels of reactive oxygen species (ROS), including semiquinone radicals, peroxides, and hydroxyl radicals (Barbehenn et al. 2003, $2005 \mathrm{a}, \mathrm{b})$. The production of ROS is associated with oxidative damage to nutrients in the gut lumen and oxidative stress in gut tissues (Summers and Felton 1994; Barbehenn et al. 2005a). Thus, AO might act synergistically with phenolics to increase their pro-oxidant effects on herbivores. Oxidative stress in the midgut lumen was examined with electron paramagnetic resonance (EPR) spectrometry to measure changes in free radical levels. The potential for synergism between $\mathrm{AO}$ and phenolics was examined by comparing semiquinone radical levels in larvae that fed on either low or high AO leaves coated with tannins. This work tested the hypothesis that elevated foliar AO activity (1) decreases levels of reduced ascorbate in the midgut contents of Lymantria dispar L. caterpillars, (2) produces oxidative stress in the gut lumen, and (3) decreases insect performance. To increase the generality of our results, the potential impact of AOoverexpressing poplar on ascorbate levels in the acidic guts of Melanoplus sanguinipes (Fabricius) grasshoppers was also examined.

\section{Methods and Materials}

Transgenic Poplars Hybrid poplar was chosen for this study because it is an acceptable host plant for $L$. dispar, is easily transformed, grows rapidly, and has been widely studied as a model tree in plant molecular biology and in studies of insect-plant interactions. AO-overexpressing poplars were produced by introducing the cucumber AO gene into Populus tremula $\times$ Populus alba (INRA 717I-B4) via Agrobacterium-mediated transformation using the method of Leplé et al. (1992). The complete cucumber AO-coding sequence (GenBank accession number J04494), including the signal peptide sequence, was inserted into the binary plasmid pGA643 (An et al. 1988) between the cauliflower mosaic virus $35 \mathrm{~S}$ promoter and the T7-5 terminator, giving rise to $\mathrm{pGA}-\mathrm{CAO}$, as described previously (Sanmartin et al. 2003). Putative transformed shoots were first tested by rooting ability on kanamycin, and the presence of the transgene was confirmed by using polymerase chain reaction. Independently transformed plantlets were assayed for AO activity as described below, and plants with the highest AO levels were selected and moved to a greenhouse. The high expression of the AO transgene and the size of the AO transcript were confirmed in greenhousegrown plants by Northern analysis by using a fragment of the cucumber AO gene as a probe (Sambrook and Russell 2001). Plantlets were propogated in vitro or as green cuttings and rooted in potting mix under high humidity in a mist chamber. Of the more than 10 independent transformants, three lines that showed high AO activities (designated genotype $\mathrm{AO} 1, \mathrm{AO} 2$, and $\mathrm{AO} 3$ ) were selected for further analysis. Untransformed parental stock plants served as the control (wild type) genotype. Seedlings were shipped from the University of Victoria to the University of Michigan.

Saplings were grown in a greenhouse in 8-1 "Treepots" (Hummert International, Earth City, MO, USA) in Sunshine potting mix (Type 4), with Osmocote slow-release fertilizer (14-14-14) (Scotts, Marysville, OH, USA) and watered as needed. Growth lights with $400 \mathrm{~W}$ high-pressure sodium bulbs (PL Light Systems; Beamsville, ON, Canada) were used from September to May (L16/D8). Saplings were grown to a height of $\geq 1 \mathrm{~m}$ over a period of 3-4 mo before their use in experiments. Leaves were numbered sequentially from the shoot apex using the leaf plastochron index (LPI; Larson and Isebrands 1971). The first leaf lamina with a length greater than $2 \mathrm{~cm}$ was defined as LPI 0 . Leaves for all experiments were excised with a sterile razor blade from LPI 10-20 from at least three trees of each genotype. Two to three leaves per day from each tree were excised, beginning with the upper leaves. After washing for $20 \mathrm{~min}$ in a water bath, leaf surfaces were blotted dry with paper towels and allowed to air dry with their petioles placed in tubes of water. Leaf disks were cut with a cork 
borer (23 $\mathrm{mm}$ diameter), and all disks within each genotype were mixed to randomize potential effects of leaf position and individual tree.

Insects $L$. dispar is a polyphagous tree-feeding species that has been used widely as a model herbivore in studies of plant-insect interactions. It has a mildly acidic to neutral foregut ( $\mathrm{pH}$ 5.2-7.2) and a basic midgut ranging from $\mathrm{pH}$ 8.0 to 11.0 (Schultz and Lechowicz 1986; Appel and Maines 1995). Eggs of $L$. dispar were obtained from the US Department of Agriculture (Otis Air Force Base, Massachusetts, USA). Third- and fourth-instar larvae were reared on an artificial diet prepared as described previously (Barbehenn et al. 2001), with the exceptions that linseed oil was used instead of wheat germ oil and sodium alginate (2.6\%) was added to the dry ingredients. Larvae were reared in Petri dishes in incubators at either $18^{\circ} \mathrm{C}$ or $23^{\circ} \mathrm{C}$ to regulate developmental rates. Newly molted larvae (containing empty midguts) were switched from the rearing diet to an experimental food.

M. sanguinipes is a polyphagous grasshopper that normally feeds on a wide variety of forbs and grasses but will readily accept hybrid poplar leaves. It was chosen for comparison with $L$. dispar because it has both an acidic foregut (pH 5.5) and midgut (pH 6.8; Barbehenn et al. 1996), which could permit high AO reaction rates. Eggs of a nondiapause strain were obtained from the US Department of Agriculture (Sidney, MT, USA). Nymphs were reared on romaine lettuce and wheat bran in a wire mesh cage with an adjacent $100 \mathrm{~W}$ light bulb on a L16/D8 photoperiod.

Chemical Analyses Ascorbate oxidase was analyzed in leaf disks that were stored frozen $\left(-80^{\circ} \mathrm{C}\right)$ in airtight plastic bags. Samples for analysis were collected on five dates across 2 mo during feeding experiments on first and fourth instars. Groups of three frozen disks were weighed quickly and ground with a chilled pestle and mortar in a mixture of $1.0 \mathrm{ml}$ of $\mathrm{pH} 5.6$ sodium phosphate buffer $(0.1 \mathrm{M})$ containing $1 \mathrm{mM}$ ethylenediaminetetraacetic acid (EDTA), $10 \mathrm{mg}$ polyvinyl polypyrolidone, and approximately $15 \mathrm{mg}$ sand. Leaf homogenates were centrifuged for $3 \min \left(4^{\circ} \mathrm{C}\right.$; $8,000 \times g$ ), and the supernatant solutions were used immediately for AO analysis. One-milliliter reaction mixtures contained $960 \mu \mathrm{l}$ of $\mathrm{pH} 5.6$ buffer, $20 \mu \mathrm{l}$ of ascorbate in buffer $(37.5 \mathrm{mM})$, and $20 \mu \mathrm{l}$ of the supernatant solution. The AO reaction was measured as the rate of decrease in absorbance at $290 \mathrm{~nm}$. An extinction coefficient of $2.8 \mathrm{mM}^{-1} \mathrm{~cm}^{-1}$ was used to express change in absorbance units on a molar basis (Yoshimura et al. 1998). Boiled control supernatant solutions showed no AO activity. Comparisons of $\mathrm{AO}$ activity at $\mathrm{pH} 5.6$ and 10 (70 $\mathrm{mM}$ carbonate-bicarbonate buffer) were made by using fresh leaf disks from each of three trees per AO genotype (LPI 15). Rates of ascorbate autoxidation at $\mathrm{pH}$ 10 were subtracted from the overall oxidation rates to measure the enzymatic component. AO rates were also compared by using commercial AO prepared from a Cucurbita species (Calbiochem, San Diego, CA, USA). AO activities provided by the manufacturer were $325 \mathrm{U} / \mathrm{mg}$ solid or $1,625 \mathrm{U} / \mathrm{mg}$ protein, where $1 \mathrm{U}$ was defined as the amount of enzyme that will oxidize $1.0 \mu \mathrm{mol}$ of ascorbic acid per minute at $30^{\circ} \mathrm{C}$ ( $\mathrm{pH}$ 5.6). The reaction mixtures were prepared as described above with the exception that the $\mathrm{pH} 10$ solution was prepared by adjusting the phosphate buffer with sodium hydroxide.

Ascorbate in each genotype was measured in the same collections of leaf disks used for measuring AO activity. Samples (approximately $100 \mathrm{mg}$ ) were weighed quickly and ground in liquid nitrogen to avoid artifacts caused by thawing. Frozen ground samples were transferred to $15-\mathrm{ml}$ plug-seal cap centrifuge tubes and extracted in $1.0 \mathrm{ml} 5 \%$ metaphosphoric acid (containing $1 \mathrm{mM}$ EDTA). Following a 30-min extraction with continuous mixing, samples were centrifuged $\left(1,000 \times g, 4^{\circ} \mathrm{C}, 5 \mathrm{~min}\right)$, the supernatant solutions removed, and the extraction repeated. Supernatant solutions were pooled within samples, mixed, and stored frozen $\left(-80^{\circ} \mathrm{C}\right)$ until analysis with high performance liquid chromatography (HPLC; Barbehenn 2003).

To examine the impact of ingested AO on ascorbate levels in caterpillars, ascorbate was measured in the midgut contents of fourth instars that fed for $2 \mathrm{~d}$ on leaf disks from one of the four genotypes. Midgut contents were dissected ( $N=11-13$ replicate larvae/genotype), dispersed in tared centrifuge tubes containing $300 \mu \mathrm{l}$ of $5 \%$ metaphosphoric acid, and weighed to the nearest $0.1 \mathrm{mg}$. Ascorbate was measured with HPLC as described above.

Ascorbate was measured in adult M. sanguinipes after they fed on either a mixture of leaf disks from control genotype trees ( $N=15$ insects) or a mixture of leaf disks from all three AO-overexpressing genotypes $(N=15$ insects). Grasshoppers were placed in individual containers in a $26^{\circ} \mathrm{C}$ incubator and were starved overnight to clear their guts and stimulate rapid feeding. Insects were dissected soon after they had eaten one or more leaf disks to ensure that their foreguts and midguts were full. Sample collection and ascorbate analysis were done as described above, with the exception that the foregut and midgut contents were extracted in 400 and $250 \mu$ of metaphosphoric acid, respectively. Ascorbate was measured in a haphazard subset of the collected samples $(N=8-10$ per genotype and site), since this was sufficient to determine the effects of $\mathrm{AO}$ on ascorbate levels in M. sanguinipes.

Oxidative Stress in the Midgut To test the hypothesis that AO-overexpressing leaves have a synergistic effect on the oxidation of phenolics, leaf disks from the control genotype 
and AO2 (LPI 13 and 14) were prepared as described above and treated with $20-\mu 1$ aliquots of a tannin solution, producing an increase of $7.5 \%$ dry weight of pedunculagin and $7.5 \%$ pentagalloyl glucose. Fourth instars $(N=9)$ fed on the leaf disks for $18-22 \mathrm{hr}\left(18^{\circ} \mathrm{C}\right)$, following which the levels of semiquinone radicals in midgut contents, were measured with EPR spectrometry. Sample preparation and EPR analyses were performed as described previously (Barbehenn et al. 2005a). Briefly, midgut contents were dissected, weighed in a tared centrifuge tubes containing $300 \mu \mathrm{l}$ of $\mathrm{pH} 10$ carbonate buffer (containing 10\% dimethylsulfoxide), dispersed, and then centrifuged. Supernatant solutions $(200 \mu \mathrm{l})$ were placed directly in a flat cell in the EPR sample cavity, and the resulting first derivative spectra were integrated with WinEPR software. Radical levels were calculated in the midgut fluid volumes (approximately $90 \%$ of the mass) using 2,2,6,6-tetramethyl-1-piperidinyloxy radical standards. A synergistic effect would be indicated by the presence of higher semiquinone concentrations in the midgut contents of larvae that fed on the AO-overexpressing genotypes. At the time of dissection, all larvae were found to have produced dark frass pellets and to have full midguts, indicating that they fed well on the treated disks.

The potential for commercial AO (Calbiochem; purified from Cucurbita sp.) to produce oxidative stress in caterpillars was examined by measuring free radicals in the midgut contents of fourth instars that fed on AO-treated leaf disks from the control genotype. AO was suspended in 50\% acetone (containing $5.7 \mathrm{mg} / \mathrm{ml}$ sucrose) at $0.33 \mathrm{mg} / \mathrm{ml}$ (low level) and $1.6 \mathrm{mg} / \mathrm{ml}$ (high level). Leaves were cut and prepared from LPI 10-20 as described above. Leaf disks were treated with $20-\mu 1$ aliquots of either the high or low AO suspensions or the AO-free control solution. Based on a recovery of AO activity from treated leaves of $33 \%( \pm 2 \%$, $N=6$ ), we calculated that the AO activity of control genotype leaves was increased by fourfold (low level) or 20 -fold (high level). Newly molted larvae were placed at random on each of the three treatment groups and fed poplar leaf disks for a 2-d period. Freshly treated disks were provided daily, and a moist filter paper was placed in each plastic cup to maintain leaf turgidity. Larvae were fed fresh disks prior to examination of their gut contents on the third day with EPR spectrometry. Between eight and 10 larvae were examined in each treatment group. This experiment was repeated 1 wk later with a different set of saplings.

Larval Performance To confirm that the performance of $L$. dispar larvae is affected by the absence of ascorbic acid from their food, performance was measured in fourth instars on artificial diet containing either $2.5 \%$ dry weight ascorbic acid or diet containing no ascorbic acid. The ascorbate-free diet contained an additional 2.5\% DW cellulose instead of ascorbate. Newly molted fourth instars were assigned at random to the two diets. Larvae were fed with freshly prepared diets daily and kept in individual 35 -ml plastic cups in a $23^{\circ} \mathrm{C}$ incubator (L16/D8). Upon molting to the fifth instar, larvae were frozen and then dried to determine their final weights. Initial larval dry weights were determined by using a fresh weight/dry weight ratio from newly molted fourth instars. Frass was collected and weighed after drying to completion $\left(70^{\circ} \mathrm{C}\right)$. Previous work found no effects of ascorbate concentration on the approximate digestibility of an artificial diet (Lindroth and Weiss 1994), and therefore, frass production was measured to compare the amounts of each diet consumed. Relative egestion rate (RER) was defined as milligram frass per milligram initial body mass per day. Relative growth rate (RGR) was measured as milligram growth per milligram initial body mass per day. RER and RGR were measured on a dry mass basis.

The performance of first instars was measured on the control and transgenic genotypes. Newly hatched larvae were randomly assigned to each genotype ( $N=15$ larvae/ genotype). Larval fresh weights were measured to the nearest $0.01 \mathrm{mg}$ on a Cahn 25 Electobalance (Cahn Instruments, Cerritos, CA, USA) and converted to dry weights based on fresh weight/dry weight ratios of five killed larvae. Larvae were kept in individual plastic cups, as described above. Leaf disks were prepared daily, also as described above. A moist filter paper was placed in each cup to maintain the water content of the leaf disks. To estimate the amount consumed by each larva, frass pellets were collected and dried daily $\left(70^{\circ} \mathrm{C}\right)$ during the first instar. Upon molting to the second instar, larvae were frozen, dried, and weighed.

This experiment was repeated using newly molted fourth instars. To measure consumption, fresh weights of leaf disks fed to each larva were recorded, and fresh weight/dry weight ratios of representative leaf disks $(N=5)$ from each genotype were measured daily to convert food fresh weights to dry weights. The difference between the dry weight of the food and the dry weight of the uneaten remains was defined as the amount consumed. Approximate digestibility (AD) was measured as ( $\mathrm{mg}$ ingested $-\mathrm{mg}$ egested) $/ \mathrm{mg}$ ingested $\times$ 100. Efficiency of conversion of digested matter to body mass (ECD) was measured as $\mathrm{mg}$ growth/(mg ingested $-\mathrm{mg}$ egested) $\times 100$. Efficiency of conversion of ingested matter to body mass (ECI) was measured as $\mathrm{mg}$ growth $/ \mathrm{mg}$ ingested $\times$ 100 (Waldbauer 1968).

Third-instar $L$. dispar were used to compare larval performance on the intact plants of each genotype. The third instar was chosen to ensure that sufficient leaf material was available to complete this developmental stage. Newly molted larvae were weighed initially and placed at random on separate leaves in fine nylon mesh bags, which were tied 
around the petioles. Trees were maintained in the greenhouse (16-hr photoperiod), and pots were rotated daily to provide even exposure of light and heat to all larvae. Five larvae were bagged (one larva per leaf) on four trees per genotype, using leaf LPI 12 through 16. Less than $5 \%$ of each leaf was eaten over a 4-d period. Frass was recovered from each bag at the end of the third instar and dried at $70^{\circ} \mathrm{C}$. Larvae were frozen upon molting to the fourth instar and then dried to determine their final weights. Larval fresh weights at the beginning of the experiment were converted to dry weights using fresh weight/dry weight ratios from six representative larvae. RER was measured in lieu of RCR.

Statistical Analysis AO activity and ascorbate levels in the four genotypes were compared with one-way analysis of variance (ANOVA; SAS 2003). The normality of residuals was tested with Proc Univariate. Pairwise comparisons between genotypes were made by differences of least squares means ( $P=0.05$ for a priori comparisons). To test the hypothesis that the control genotype differed from the three AO genotypes, these two groups were compared with contrasts (weighted as $-3,1,1,1$ ) (Proc Mixed). Ascorbate concentrations in midgut fluids of larvae were compared across genotypes and by contrasts, as described above. Ascorbate levels in the foreguts and midguts of $M$. sanguinipes were compared with two-way ANOVA, using plant genotype and gut site as main effects. Ascorbyl radical levels in $L$. dispar fed AO-treated leaf disks were compared across treatment levels with one-way ANOVA. Comparison between levels of semiquinone radicals in $L$. dispar fed control genotype foliage treated with tannins and $\mathrm{AO} 2$ foliage treated with tannins were made with the Kruskal-Wallis test (Wilkinson 2000).

RCR, RER, RGR, and nutritional indices (AD, ECD, and ECI) were compared across artificial diets or tree genotypes with analysis of covariance (ANCOVA; Proc Mixed). Main effects used in all models were ascorbate level or tree genotype, respectively. ANCOVA models used to compare insect performance across poplar genotypes were as follows: RGRs were compared with growth rate as the dependent variable and initial dry mass as the covariate. RERs and RCRs were compared across treatments or genotypes with egestion rate or consumption rate as the dependent variable and initial dry mass as the covariate. Developmental times and growth were compared with one-way ANOVA (diet experiment) or ANOVA with contrasts (poplar experiments). ADs were compared by using frass production as the dependent variable and ingested mass as the covariate. ECDs were compared by using growth as the dependent variable and mass digested as the covariate. ECIs were compared with growth as the dependent variable and mass ingested as the covariate. In all cases, models testing for a significant interaction between the dependent variable and covariate were first tested to confirm that the regression slopes were parallel. To test the hypothesis that larvae on the control genotype differed from larvae on the three AO genotypes, these two groups were compared with contrasts, as described above. Where necessary, log or square root transformations were used to normalize residuals, and where indicated, statistical outliers were removed. Data that could not be transformed to meet the assumptions of ANOVA were analyzed with Kruskal-Wallis tests (Wilkinson 2000). Individual insects were used as replicates in all experiments.

\section{Results}

Transgenic poplars overexpressing the cucumber AO gene were produced by Agrobacterium-mediated transformation, and lines (genotypes) were selected based on transcript accumulation (Fig. 1) and elevated AO activity. AO activities (measured at $\mathrm{pH}$ 5.6) were increased by 14- to 37 -fold in the transgenic genotypes compared with the control (wild type) genotype (Table 1). Sapling growth rates and leaf morphology showed no obvious differences between AO-overexpressing and untransformed lines when grown to a height of approximately $2 \mathrm{~m}$. However, ascorbate levels in the AO-overexpressing genotypes were significantly lower by $19-54 \%$, compared with the control genotype (contrast $P=0.005$; Table 1 ). Thus, AO activity was negatively correlated with ascorbate levels in the poplars $\left(R^{2}=0.883\right.$; Fig. 2$)$. However, when $\mathrm{AO}$ activity in AO-overexpressing leaves was measured in $\mathrm{pH} 10.0$ reaction mixtures (representative of many caterpillar midguts), it was reduced to $9 \%$ of the activity at $\mathrm{pH} 5.6$ (representative of caterpillar and grasshopper foreguts). Similarly, the activity of purified cucumber $\mathrm{AO}$ at $\mathrm{pH}$ 10.0 was only $5 \%$ of its activity at $\mathrm{pH}$ 5.6.

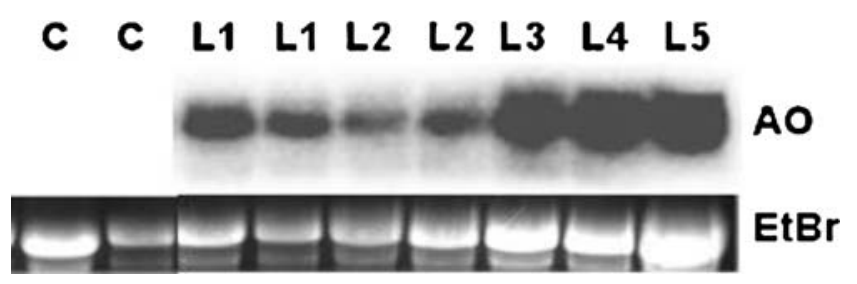

Fig. 1 Northern blot comparing expression of cucumber AO in control (wild type) and transgenic poplar. The blot was probed with a ${ }^{32} \mathrm{P}$-labeled fragment of the AO-coding sequence. Ethidium bromidestained ribosomal RNA bands $(E t B r)$ are shown as loading controls. $C$ refers to untransformed control lines and $L 1-L 5$ represent confirmed $\mathrm{AO}-$ overexpressing lines. Lanes with different designations are from independently transformed lines, and lanes sharing the same designation represent separate individuals from the same line. L1, $L 4$, and $L 5$ were used in subsequent experiments and were designated genotypes $\mathrm{AO} 1, \mathrm{AO} 2$ and $\mathrm{AO} 3$, respectively. No AO RNA bands were visible in the control lines 
Table 1 Ascorbate oxidase (AO) activity and ascorbate levels in control (wild type) and transgenic poplar genotypes

\begin{tabular}{lll}
\hline Genotype & $\begin{array}{l}\text { Ascorbate oxidase } \\
\left(\mu \mathrm{mol} \mathrm{min} \mathrm{m} \mathrm{FW}^{-1}\right)\end{array}$ & $\begin{array}{l}\text { Ascorbate } \\
(\mu \mathrm{mol} / \mathrm{g} \mathrm{FW})\end{array}$ \\
\hline Control & $17.1 \pm 3.3 \mathrm{a}$ & $6.8 \pm 0.6 \mathrm{c}$ \\
$\mathrm{AO1}$ & $276.5 \pm 73.3 \mathrm{~b}$ & $5.5 \pm 0.5 \mathrm{bc}$ \\
$\mathrm{AO} 2$ & $642.5 \pm 67.2 \mathrm{c}$ & $3.1 \pm 0.8 \mathrm{a}$ \\
AO3 & $250.3 \pm 76.8 \mathrm{~b}$ & $4.4 \pm 0.8 \mathrm{ab}$ \\
Significance of effects & & \\
Genotype & $P<0.001$ & $P=0.008$ \\
Contrast & $P<0.001$ & $P=0.005$ \\
\hline
\end{tabular}

Samples of each genotype were analyzed from five dates for ascorbate oxidase and seven dates for ascorbate.

When L. dispar larvae consumed leaves from the control or AO-overexpressing genotypes, ascorbate levels did not differ in their midgut contents when contrasted between both types (Fig. 3; $P=0.480$ ). Thus, AO activity in the control and AO-overexpressing genotypes was not associated with larval ascorbate levels $\left(R^{2}=-0.112\right)$. Regardless of the genotype ingested, ascorbate in the midgut contents dropped to only $7.0 \%( \pm 0.5)$ of foliar ascorbate levels. Similarly, in $M$. sanguinipes, there were no significant differences between ascorbate levels in the foreguts of adults on control or AO leaf disks $(3.0 \pm 0.7$ and $3.2 \pm 0.7 \mathrm{mM}$, respectively) or in the midguts of adults on control or $\mathrm{AO}$ leaf disks $(0.16 \pm 0.03$ and $0.16 \pm 0.04 \mathrm{mM}$, respectively; genotype effect $P=0.818)$. Foreguts contained more ascorbate than midguts (gut site effect, $P<0.001$ ), but there was no significant genotype $\times$ gut site interaction $(P=0.830)$.

Contrary to expectation, L. dispar that fed on AO leaf disks coated with tannins did not have significantly higher levels of oxidative stress than larvae that fed on control genotype leaf disks treated with tannins. Semiquinone

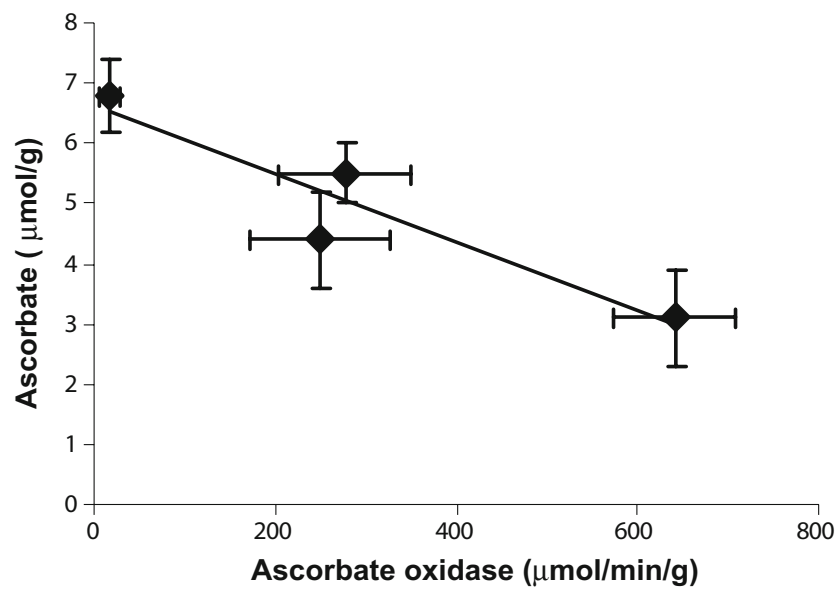

Fig. 2 Negative association between AO activity and ascorbate levels in control and AO-overexpressing poplar leaves $\left(R^{2}=0.883\right)$. Standard error bars are presented

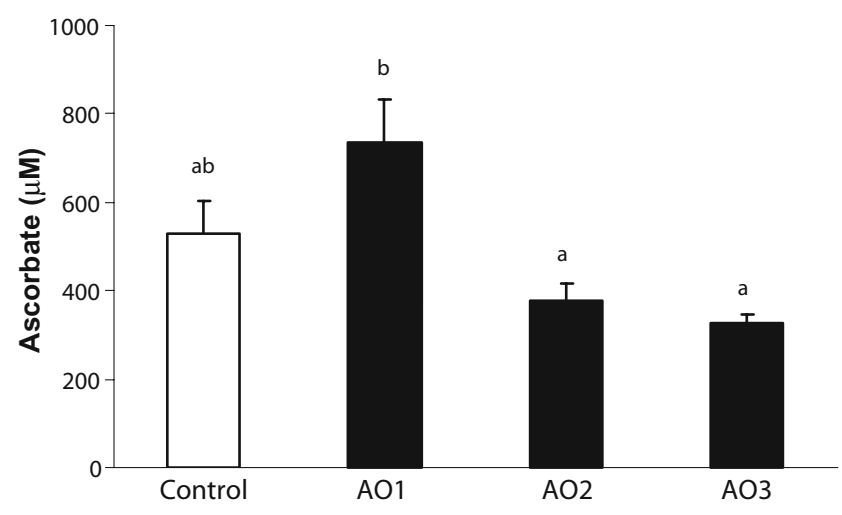

Fig. 3 Ascorbate concentrations in the midgut fluids of fourth-instar Lymantria dispar larvae after feeding on control or AO poplar genotype leaf disks. No significant differences were observed between larvae that fed on AO genotypes compared to the control genotype (contrast $P=0.480$ )

radical concentrations in the midgut contents were $10.6 \pm$ 1.5 and $8.9 \pm 1.7 \mu \mathrm{M}$ in larvae on the $\mathrm{AO}$ transgenic and control genotype foliage, respectively $(P=0.233)$. The consumption of AO-coated leaf disks also had no significant effect on oxidative stress in the midgut; similar levels of ascorbyl radicals were present in the midgut across $\mathrm{AO}$ treatment levels in the first experiment (229-293 nM; $P=$ $0.644)$ and in the second experiment (119-147 nM; $P=$ 0.831). A similar experiment performed on final-instar Orgyia leucostigma larvae also showed a lack of effect from feeding on AO-treated leaf disks $(P=0.570$; unpublished data). No further work was performed on the potential effects of elevated AO levels in transgenic poplar on oxidative stress, since there was no effect of elevated AO levels on ascorbate or phenolic oxidation in $L$. dispar larvae.

When L. dispar larvae consumed artificial diet that lacked ascorbate, their performance was significantly decreased: weight gain decreased, developmental time increased, and RGR decreased (Table 2). Relative egestion rate was also decreased in larvae on the ascorbate-free diet, potentially explaining their decrease in performance. However, an analysis of larval growth rate adjusted for frass production (ANCOVA; Fig. 4) demonstrated that the effect of ascorbate was primarily post-ingestive. For any given level of frass production (directly proportional to consumption), larvae on the ascorbate-containing diet had higher growth rates than did larvae on the ascorbate-free diet.

Relative egestion rates did not differ between first-instar caterpillars on the control genotype and the AO-overexpressing genotypes (contrast $P=0.161$; Table 3 ), suggesting that consumption rates did not differ as a result of $\mathrm{AO}$ overexpression. Relative growth rates of first-instar caterpillars also did not differ significantly between larvae on the control genotype and the AO-overexpressing genotypes (contrast $P=0.515$ ). Similarly, third instars that fed in mesh bags on intact saplings also showed no effect of the high 
Table 2 Effects of ascorbic acid on fourth-instar Lymantria dispar performance on artificial diets

\begin{tabular}{llcrr}
\hline Diet & Relative egestion rate & Growth $(\mathrm{mg})$ & Development time (days) & Relative growth rate \\
\hline +Ascorbic acid & $0.881 \pm 0.159 \mathrm{~b}$ & $16.1 \pm 3.2 \mathrm{~b}$ & $5.1 \pm 0.8 \mathrm{a}$ & $0.349 \pm 0.072 \mathrm{~b}$ \\
-Ascorbic acid & $0.548 \pm 0.156 \mathrm{a}$ & $9.6 \pm 0.8 \mathrm{a}$ & $7.0 \pm 0.4 \mathrm{~b}$ & $0.143 \pm 0.068 \mathrm{a}$ \\
Significance of effects & $P<0.001$ & $P<0.001$ & $P=0.004$ & $P<0.001$ \\
Diet & & & 15 \\
\hline
\end{tabular}

Larvae were fed artificial diets. Comparisons of RER and RGR were made using ANCOVA, with initial dry weight as the covariate. $\mathrm{RCR}=\mathrm{mg}$ ingested/mg initial body mass/day; $\mathrm{RGR}=\mathrm{mg}$ growth/mg initial body mass/day

AO activities in the transgenic genotypes on their RER (contrast $P=0.411$ ) or RGR (contrast $P=0.760$; Table 4). It was assumed that AO activities were unaffected by larval feeding, since no evidence of AO induction by caterpillars has been observed in hybrid poplar (Major and Constabel 2006; Ralph et al. 2006). Finally, the consumption and growth rates and nutritional indices (AD, ECD, and ECI) of fourth instars did not differ when contrasted between the control and AO-overexpressing genotypes (contrast $P$ 's $\geq$ 0.690; Table 5). Unlike larvae on an artificial diet without ascorbate, larval growth and developmental times were not significantly altered in L. dispar on AO-overexpressing genotypes (data not shown).

\section{Discussion}

Contrary to our hypothesis, elevated AO levels in ingested leaf tissues did not compromise the ascorbate-based antioxidant defenses in the midgut lumen of $L$. dispar. As a result, no synergistic interactions were found between $\mathrm{AO}$ and tannins on oxidative stress levels in the midguts of $L$. dispar. Neither ingested AO purified from Cucurbita or overexpressed in poplar were able to change ascorbate or ascorbyl free radical levels in the midguts of $L$. dispar. Similarly, consumption of AO-overexpressing poplar leaves

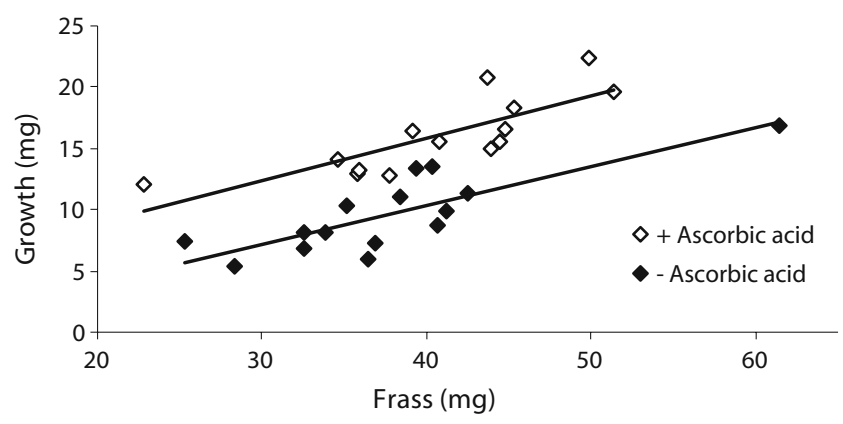

Fig. 4 Effect of ascorbate on growth of fourth-instar Lymantria dispar larvae on artificial diets. Previous work showed no effect of ascorbate on the digestibility of the diet, so frass was measured as an estimate of ingestion. In this case, ANCOVA on growth using frass as a covariate provides a comparison of food utilization efficiencies analogous to comparing ECI (efficiency of conversion of ingested matter to body mass) by the grasshopper $M$. sanguinipes had no impact on levels of ascorbate along the length of its gut. It is noteworthy that ascorbate levels in the guts of $M$. sanguinipes that fed on wheat leaves (Barbehenn 2003) were similar to levels measured in this study on poplar, suggesting that poplar does not have an unusual impact on the post-ingestive fate of ascorbate. The large drop in ascorbate levels observed in the midguts of $L$. dispar on poplar are presumed to be the result of ascorbate oxidation by non-AO reactions, since such decreases in ascorbate concentration can also occur in the midguts of caterpillars feeding on an artificial diet (Barbehenn et al. 2001).

Larval performance was unaffected by high levels of $\mathrm{AO}$, consistent with the inability of ingested AO to oxidize ascorbate in the midgut contents of the tested caterpillars. The results of our artificial diet study suggest that, had AO greatly decreased ascorbate levels available to $L$. dispar larvae, performance would have been decreased as a result of post-ingestive effects on growth rates (Horton and Redak 1993; cf. Lindroth and Weiss 1994). The lack of effect of high levels of AO on midgut ascorbate levels, oxidative stress, or performance calls into question how AO might function more effectively in a wide variety of other plantinsect interactions.

The low levels of oxygen present in the guts of caterpillars and grasshoppers may limit post-ingestive $\mathrm{AO}$

Table 3 Effects of AO transgenic poplars on the performance of firstinstar Lymantria dispar on leaf disks

\begin{tabular}{llll}
\hline Genotype & $\begin{array}{l}\text { Relative } \\
\text { egestion rate }\end{array}$ & $\begin{array}{l}\text { Relative } \\
\text { growth rate }\end{array}$ & $N$ \\
\hline Control & $1.98 \pm 0.09 \mathrm{a}$ & $0.742 \pm 0.043 \mathrm{~b}$ & 14 \\
$\mathrm{AO} 1$ & $2.17 \pm 0.08 \mathrm{~b}$ & $0.729 \pm 0.036 \mathrm{~b}$ & 14 \\
$\mathrm{AO2}$ & $1.83 \pm 0.07 \mathrm{a}$ & $0.626 \pm 0.032 \mathrm{a}$ & 13 \\
$\mathrm{AO3}$ & $2.26 \pm 0.05 \mathrm{~b}$ & $0.781 \pm 0.026 \mathrm{~b}$ & 14 \\
Significance of effects & & & \\
Genotype & $P<0.001$ & $P=0.015$ & \\
Contrast $^{\mathrm{a}}$ & $P=0.161$ & $P=0.515$ & \\
\hline
\end{tabular}

Comparisons between genotypes were made using ANCOVA with initial dry weight as the covariate.

$\mathrm{RER}=\mathrm{mg}$ frass $/ \mathrm{mg}$ initial body mass/day; $\mathrm{RGR}=\mathrm{mg}$ growth $/ \mathrm{mg}$ initial body mass/day

${ }^{\mathrm{a}}$ Contrast between control genotype and three AO genotypes 
Table 4 Effects of AO transgenic poplars on the performance of third-instar Lymantria dispar on intact tree leaves (contrast between control genotype and three AO genotypes)

\begin{tabular}{llll}
\hline Genotype & $\begin{array}{l}\text { Relative } \\
\text { Egestion Rate }\end{array}$ & $\begin{array}{l}\text { Relative } \\
\text { Growth Rate }\end{array}$ & $N$ \\
\hline Control & $1.39 \pm 0.06 \mathrm{a}$ & $0.536 \pm 0.027 \mathrm{a}$ & 20 \\
$\mathrm{AO1}$ & $1.40 \pm 0.07 \mathrm{a}$ & $0.548 \pm 0.029 \mathrm{a}$ & 20 \\
$\mathrm{AO2}$ & $1.31 \pm 0.05 \mathrm{a}$ & $0.547 \pm 0.019 \mathrm{a}$ & 20 \\
AO3 & $1.47 \pm 0.08 \mathrm{a}$ & $0.544 \pm 0.031 \mathrm{a}$ & 20 \\
Significance of effects & & & \\
Genotype $_{\text {Contrast }}{ }^{\mathrm{a}}$ & $P=0.307$ & $P=0.975$ & \\
\hline
\end{tabular}

Larvae were placed individually in mesh bags on tree leaves. All comparisons were made using ANCOVA.

$\mathrm{RER}=\mathrm{mg}$ frass/mg initial body mass/day; $\mathrm{RGR}=\mathrm{mg}$ growth $/ \mathrm{mg}$ initial body mass/day

activity in these herbivores. The $K_{\mathrm{m}}$ of AO for oxygen is $0.5 \mathrm{mM}$ (Strothkamp and Dawson 1978), while midgut oxygen levels in caterpillars are commonly on the order of $0-0.01 \mathrm{mM}$, and the foregut and midgut of M. sanguinipes have lower oxygen levels than are found in most caterpillars (Johnson and Barbehenn 2000). The large foregut of L. dispar has a relatively high oxygen level compared with the foreguts of other caterpillars (approximately $0.06 \mathrm{mM}$ in larvae on artificial diet). However, our results showed that any potential AO activity in the foregut had an inconsequential effect on the levels of ascorbate available to $L$. dispar for absorption or antioxidant defense of the midgut. Other taxa of insect herbivores that have been examined to a more limited extent, including a beetle (Coleoptera) and several grasshoppers, also have nearly anoxic gut contents (Johnson and Barbehenn 2000; Krishnan et al. 2007).

A second factor that also may limit AO activity in the midguts of caterpillars is high $\mathrm{pH}$. At the extremely basic $\mathrm{pH}$ typical of caterpillar midguts (e.g., $\mathrm{pH} 10$ ), rates of ascorbate oxidation by $\mathrm{AO}$ from transgenic poplar and
Cucurbita maxima were reduced to less than $10 \%$ of their rates at an acidic $\mathrm{pH}$ (Maccarrone et al. 1993; this study). However, the lack of extensive AO activity in the acidic foreguts of either $L$. dispar or $M$. sanguinipes suggests that low oxygen level may be the main factor limiting the oxidation of ascorbate by ingested AO.

If post-ingestive conditions limit $\mathrm{AO}$ activity, preingestive AO activity would be a plausible alternative mode of action. Neither oxygen nor high $\mathrm{pH}$ would limit $\mathrm{AO}$ activity at a herbivore-damaged leaf edge or during ingestion. However, if pre-ingestive $\mathrm{AO}$ activity were an important defense mechanism, one might expect greater treatment effects than were observed in this study. No AO effects on the performance of $L$. dispar were observed for neonate and fourth instars on leaf disks or for third instars on intact saplings.

Since high AO levels in the AO-overexpressing genotypes were not able to eliminate ascorbate in the midgut in either of the species tested in this study, our conclusions differ substantially from previous work on the potential role of $\mathrm{AO}$ as an inducible plant defense (Felton and Summers 1993). Previous work on induced plants did not isolate the effects of $\mathrm{AO}$ from those of other enzymes and nonenzymatic defenses (e.g., Bi et al. 1997). It is possible that effects ascribed to AO previously, such as the loss of ascorbate from the midgut contents of $H$. zea larvae, were produced by other enzymes that can function in the caterpillar midgut, such as peroxidases (unpublished data). It is also unclear to what extent the damage caused to nutrients by AO activity in vitro in oxygenated solutions is relevant to the low-oxygen conditions found in vivo. Finally, measurement of $\mathrm{AO}$ activity in the gut contents of caterpillars presents a quandary, since assays for $\mathrm{AO}$ are done at ambient oxygen levels, but $\mathrm{AO}$ in the gut is present at nearly anoxic levels. Presumably, the low levels of AO activity measured in the gut lumen and regurgitate of $\mathrm{H}$. zea would be even lower or negligible in the low-oxygen conditions found in vivo.

Table 5 Effects of AO-overexpressing poplars on fourth-instar Lymantria dispar performance

\begin{tabular}{|c|c|c|c|c|c|c|}
\hline Genotype & RCR & RGR & $\mathrm{AD}$ & ECD & ECI & $N$ \\
\hline Control & $2.15 \pm 0.05 \mathrm{a}$ & $0.373 \pm 0.012 b$ & $37.1 \pm 0.6 \mathrm{a}$ & $46.8 \pm 0.9 \mathrm{~b}$ & $17.3 \pm 0.2 b$ & 11 \\
\hline $\mathrm{AO} 1$ & $2.10 \pm 0.08 \mathrm{a}$ & $0.401 \pm 0.015 \mathrm{c}$ & $37.1 \pm 0.9 \mathrm{a}$ & $52.2 \pm 1.6 \mathrm{c}$ & $19.1 \pm 0.3 \mathrm{c}$ & 12 \\
\hline $\mathrm{AO} 2$ & $2.17 \pm 0.10 \mathrm{a}$ & $0.354 \pm 0.017 b$ & $38.2 \pm 0.6 \mathrm{a}$ & $42.9 \pm 1.0 \mathrm{a}$ & $16.3 \pm 0.3 \mathrm{a}$ & 10 \\
\hline $\mathrm{AO} 3$ & $1.93 \pm 0.06 \mathrm{a}$ & $0.317 \pm 0.013 \mathrm{a}$ & $36.9 \pm 0.6 \mathrm{a}$ & $44.4 \pm 1.1 \mathrm{ab}$ & $16.3 \pm 0.3 \mathrm{a}$ & 12 \\
\hline \multicolumn{7}{|c|}{ Significance of effects } \\
\hline Genotype & $P=0.072$ & $P<0.001$ & $P=0.147$ & $P<0.001$ & $P<0.001$ & \\
\hline Contrast $^{\mathrm{a}}$ & $P=0.945$ & $P=0.783$ & $P=0.834$ & $P=0.745$ & $P=0.690$ & \\
\hline
\end{tabular}

Larvae were fed leaf disks. All comparisons were made using ANCOVA, with the exception of RCR, which was analyzed with ANOVA after log transformation of these data.

$\mathrm{RCR}=\mathrm{mg}$ ingested $/ \mathrm{mg}$ initial body mass/day. $\mathrm{RGR}=\mathrm{mg}$ growth $/ \mathrm{mg}$ initial body mass $/$ day. $\mathrm{AD}=(\mathrm{mg}$ ingested $-\mathrm{mg}$ egested $) / \mathrm{mg}$ ingested $\times 100$. $\mathrm{ECD}=\mathrm{mg}$ growth $/(\mathrm{mg}$ ingested $-\mathrm{mg}$ egested $) \times 100 . \mathrm{ECI}=\mathrm{mg}$ growth $/ \mathrm{mg}$ ingested $\times 100$

${ }^{a}$ Contrast between control genotype and three AO genotypes 
A variety of ecological functions of induced AO have been examined recently, including responses to stresses such as wounding, pathogens, salinity, and heat (Bi et al. 1997; Sanmartin et al. 2003, 2007; Yamamoto et al. 2005; Fotopoulos et al. 2006; Pignocchi et al. 2006). AO activity in damaged or infected leaf areas would potentially increase the effectiveness of oxidative defenses against microbes that gain entry via insect-feeding sites (e.g., Harris et al. 1980). The formation of ROS is part of the antimicrobial response in plants (Bolwell and Wojtaszek 1997). With decreased ascorbate levels, oxidases such as polyphenol oxidase and peroxidase would have increased net rates of production of quinones and other ROS. Therefore, it may be difficult to distinguish between anti-pathogen and antiherbivore reactions when plant stress responses such as $\mathrm{AO}$ are induced.

In summary, the lack of effect of elevated levels of $\mathrm{AO}$ in poplar on ascorbate or ascorbyl radical levels in the midgut contents of $L$. dispar is consistent with the lack of effect of elevated levels of $\mathrm{AO}$ on larval performance. The lack of effect of $\mathrm{AO}$ on ascorbate levels in the grasshopper $M$. sanguinipes suggests that $\mathrm{AO}$ activity is also limited in the guts of insects with acidic $\mathrm{pH}$. As in previous work on polyphenol oxidase-overexpressing poplars (Barbehenn et al. 2007), we conclude that low oxygen levels appear to limit the effectiveness of these oxygen-dependant enzymes as postingestive defenses against a variety of leaf-chewing insects.

Acknowledgments This project was supported by the National Research Initiative of the USDA Cooperative State Research, Education and Extension Service, grant number 2004-35302-14840 to RVB and CPC. We thank Juha-Pekka Salminen for providing pedunculagin and pentagalloyl glucose, John Tanner for providing L. dispar eggs, Stefan Jaronski for providing M. sanguinipes eggs, Cara Mozola for measuring AO activity, Grace Lee for measuring ascorbate, and Robin Mellway for assistance in transforming the poplar.

\section{References}

AN, G., EBERT, P. R., Mitra, A., and HA, S. B. 1988. Binary vectors, pp. 1-19, in S. B. Gelvin, and R. A. Schilperoort (eds.). Plant Molecular Biology Manual. Kluwer, Dordrecht, The Netherlands.

Appel, H. M., and MAINES, L. W. 1995. The influence of host plant on gut conditions of gypsy moth (Lymantria dispar) caterpillars. $J$. Insect Physiol. 41:241-246.

BARBEHENN, R. V. 2003. Antioxidants in grasshoppers: higher levels defend the midgut tissues of a polyphagous species than a graminivorous species. J. Chem. Ecol. 29:683-702.

Barbehenn, R. V., Martin, M. M., and Hagerman, A. E. 1996. Reassessment of the roles of the peritrophic envelope and hydrolysis in protecting polyphagous grasshoppers from ingested hydrolyzable tannins. J. Chem. Ecol. 22:1901-1919.

BarbehenN, R. V., Bumgarner, S. L., Roosen, E., and Martin, M. M. 2001. Antioxidant defenses in caterpillars: role of the ascorbate recycling system in the midgut lumen. J. Insect Physiol. 47:349-357.
BarbehenN, R. V., Poopat, U., and Spencer, B. 2003. Semiquinone and ascorbyl radicals in the gut fluids of caterpillars measured with EPR spectrometry. Insect Biochem. Mol. Biol. 33:125-130.

BarbehenN, R. V., Cheek, S., Gasperut, A., Lister, E., and MABEN, R. 2005a. Phenolic compounds in red oak and sugar maple leaves have prooxidant activities in the midguts of Malacosoma disstria and Orgyia leucostigma caterpillars. J. Chem. Ecol. 31:969-988.

Barbehenn, R., Dodick, T., Poopat, U., and Spencer, B. 2005 b. Fenton-type reactions and iron concentrations in the midgut fluids of tree-feeding caterpillars. Arch. Insect Biochem. Physiol. 60:32-43.

Barbehenn, R. V., Jones, C. P., Yip, L., Tran, L., and Constabel, C. P. 2007. Limited impact of elevated levels of polyphenol oxidase on tree-feeding caterpillars: assessing individual plant defenses with transgenic poplar. Oecologia 154:129-140.

BI, J. L., and Felton, G. W. 1995. Foliar oxidative stress and insect herbivory: primary compounds, secondary metabolites, and reactive oxygen species as components of induced resistance. $J$. Chem. Ecol. 21:1511-1530.

Bi, J. L., Murphy, J. B., and Felton, G. W. 1997. Antinutritive and oxidative components as mechanisms of induced resistance in cotton. J. Chem. Ecol. 23:97-117.

Bolwell, G. P., and WojtaszeK, P. 1997. Mechanisms for the generation of reactive oxygen species in plant defence- a broad perspective. Physiol. Mol. Plant Pathol. 51:347-366.

Duffey, S. S., and Stout, M. J. 1996. Antinutritive and toxic components of plant defense against insects. Arch. Insect Biochem. Physiol. 32:3-37.

FElton, G. W., and DufFeY, S. S. 1992. Ascorbate oxidation reduction in Helicoverpa zea as a scavenging system against dietary oxidants. Arch. Insect Biochem. Physiol. 19:27-37.

Felton, G. W., and Summers, C. B. 1993. Potential role of ascorbate oxidase as a plant defense protein against insect herbivory. $J$. Chem. Ecol. 19:1553-1568.

Fotopoulos, V., SANMARTin, M., and KANELlis, A. K. 2006. Effect of ascorbate oxidase over-expression on ascorbate recycling gene expression in response to agents imposing oxidative stress. $J$. Exp. Bot. 57:3933-3943.

Garcia-Pineda, E., CAStro-Mercado, E., and Lozoya-Gloria, E. 2004. Gene expression and enzyme activity of pepper (Capsicum annuum L.) ascorbate oxidase during elicitor and wounding stress. Plant Sci. 166:237-243.

Gonzalez-Reyes, J. A., Alcain, F. J., Caler, J. A., Serrano, A., CordobA, F., and NaVAS, P. 1995. Stimulation of onion root elongation by ascorbate and ascorbate free radical in Allium cepa L. Protoplasma 184:31-35.

Harris, M. D., Brewer, J. W., and Merril, L. D. 1980. Insect involvement in the transmission of bacterial pathogens, pp. 201292, in K. F. HARRIS, and K. MARAMOROSCH (eds.). Vectors of Plant Pathogens. Academic, New York, USA.

HermsmeIER, D., SchitTKo, U., and BALDwin, I. T. 2001. Molecular interactions between the specialist herbivore Manduca sexta (Lepidoptera, Sphingidae) and it natural host Nicotiana attenuata. I. Large-scale changes in the accumulation of growth- and defense-related plant mRNAs. Plant Physiol. 125:683-700.

HorTON, D. R., and REDAK, R. A. 1993. Further comments on analysis of covariance in insect dietary studies. Entomol. Exp. Appl. 69:263-275.

Johnson, K. S., and BARBehenN, R. V. 2000. Oxygen levels in the gut lumens of herbivorous insects. J. Insect Physiol. 46:897-903.

KARBAN, R., and BALDWIN, I. T. 1997. Induced Responses to Herbivory. University of Chicago Press, Chicago, IL, USA.

KATO, N., and EsAKA, M. 2000. Expansion of transgenic tobacco protoplasts expressing pumpkin ascorbate oxidase is more rapid than that of wild-type protoplasts. Planta 210:1018-1022. 
Krishnan, N., Kodrik, D., Turanli, F., and Sehnal, F. 2007. Stage-specific distribution of oxidative radicals and antioxidant enzymes in the midgut of Leptinotarsa decemlineata. J. Insect Physiol. 53:67-74.

LARSON, P. R., and IsEBRANDS, J. G. 1971. The plastochron index as applied to developmental studies of cottonwood. Can. J. For. Res. 1:1-11.

Leplé, J. C., Brasileiro, A. C. M., Michel, M. F., Delmotte, F., and JouANIN, L. 1992. Transgenic poplars: expression of chimeric genes using four different constructs. Plant Cell Rep $11: 137-141$.

LINDROTH, R. L., and WeISS, A. P. 1994. Effects of ascorbic acid deficiencies on larvae of Lymantria dispar (Lepidoptera: Lymantriidae). Great Lakes Entomol. 27:169-174.

Maccarrone, M., D'Andrea, G., Salucci, M. L., Avigliano, L., and FinAZZI-Agro, A. 1993. Temperature, $\mathrm{pH}$ and UV irradiation effects on ascorbate oxidase. Phytochemistry 32: $795-798$

Major, I. T., and ConstaBel, C. P. 2006. Molecular analysis of poplar defense against herbivory. Comparison of wound- and insect elicitor-induced gene expression. New Phytol. 172:617635.

Pignocchi, C., Fletcher, J. M., Wilkinson, J. E., Barnes, J. D., and FOYER, C. H. 2003. The function of ascorbate oxidase in tobacco. Plant Physiol. 132:1631-1641.

Pignocchi, C., Kiddle, G., Hernandez, I., Foster, S. J., Asensi, A., TAYBI, T., BARNES, J., and Foyer, C. H. 2006. Ascorbate oxidase-dependent changes in the redox state of the apoplast modulate gene transcript accumulation leading to modified hormone signaling and orchestration of defense processes in tobacco. Plant Physiol. 141:423-435.

RAlPh, S., OdDY, C., COOPER, D. et al. 2006. Genomics of hybrid poplar (Populus trichocarpa $\times$ deltoides) interacting with forest tent caterpillars (Malacosoma disstria): normalized and fulllength cDNA libraries, expressed sequence tags, and cDNA microarray for the study of insect-induced defences in poplar. Mol. Ecol. 15:1275-1297.
SAmbrooK, J., and Russell, D. W. 2001. Molecular Cloning: A Laboratory Manual. 3rd edn.Cold Spring Harbor Press, Cold Spring Harbor, NY, USA.

Sanmartin, M., Drogoudi, P. D., Lyons, T., Pateraki, I., Barnes, J., and KANELLIS, A. K. 2003. Over-expression of ascorbate oxidase in the apoplast of trangenic tobacco results in altered ascorbate and glutathione redox states and increased sensitivity to ozone. Planta 216:918-928.

Sanmartin, M., Pateraki, I., Chatzopoulou, F., and Kanellis, A. K. 2007. Differential expression of the ascorbate oxidase multigene family during fruit development and in response to stress. Planta 225:873-885.

SAS Institute. 2003. The SAS system for Windows. Version 9.1. SAS Institute, Cary, NC, USA.

SchultZ, J. C., and LeCHOWICZ, M. J. 1986. Hostplant, larval age, and feeding behavior influence midgut $\mathrm{pH}$ in the gypsy moth (Lymantria dispar). Oecologia 71:133-137.

StrothKAMP, R. E., and DAWsON, C. R. 1978. A kinetic study of the effects of hydrogen peroxide and $\mathrm{pH}$ on ascorbate oxidase. Biochem. Biophys. Res. Comm. 85:655-661.

Summers, C. B., and Felton, G. W. 1994. Prooxidant effects of phenolic acids on the generalist herbivore Helicoverpa zea (Lepidoptera: Noctuiidae): potential mode of action for phenolic compounds in plant anti-herbivore chemistry. Insect Biochem. Mol. Biol. 24:943-953.

YAmamoto, A., BhuiYan, M. N. H., Waditee, R., TANAKA, Y., ESAKA, M. et al. 2005. Suppressed expression of the apoplastic ascorbate oxidase gene increases salt tolerance in tobacco and Arabidopsis plants. J. Exp. Bot. 56:1785-1796.

Yoshimura, K., ISHIKaWA, T., NAKAMURA, Y., TAMOI, M., TAKeDA, T. et al. 1998. Comparative study on recombinant chloroplastic and cytosolic ascorbate peroxidase isozymes of spinach. Arch. Biochem. Biophys. 353:55-63.

WALDBAuER, G. P. 1968. The consumption and utilization of food by insects. Adv. Insect Physiol. 5:229-289.

WILKINSON, L. 2000. SYSTAT: The system for statistics. SYSTAT, Evanston, IL, USA. 